\title{
Evaluation of egg quality characteristics of two strains of local turkey (Meleagris gallopavo) in Zaria, Kaduna State
}

${ }^{1}$ Yahaya, H. K., ${ }^{2 *}$ Olutunmogun, A. K., ${ }^{1}$ Mohammad, Y. B., ${ }^{1}$ Shettima, M. M. and ${ }^{1}$ Kabir, $\mathrm{M}$.

${ }^{I}$ Department of Animal Science, Ahmadu Bello University, Zaria, Nigeria

${ }^{2}$ National Animal Production Research Institute, Ahmadu Bello University, Shika-Zaria, Nigeria

*Corresponding author: olutunmogunkayode@yahoo.com;

Abstract +2347039338987

The study was conducted to investigate the external and internal egg quality characteristics of two local strains of turkey during their early reproductive age. A total of 96 freshly laid eggs were sampled from two local turkey strains having black and white plumages. The turkeys were 33 weeks of age with two months into lay. Data were collected weekly for three weeks on egg weight, egg length, egg diameter, shell thickness, shell weight, shell index, albumen weight, yolk weight, albumen: yolk ratio, albumen length, yolk length, albumen diameter, yolk diameter, albumen height, yolk height, yolk index and Haugh unit and analyzed using the statistical package of SAS. The results revealed that highly significant $(p<0.01)$ differences in the external traits occurred in egg weight, egg length and shell weight with the white turkey strain been superior. Also, the internal traits recorded highly significant $(p<0.01)$ differences in albumen weight, yolk weight, albumen: yolk ratio, albumen length, yolk length and yolk diameter with the white strain performing better than the black strain. Highly significant correlations ( $p>0.01$ ) exits in most of the correlated traits with the except for Haugh unit that had no significantly $(p<0.01)$ correlations. Thus, since significant variations exits between the two strains, selection activities are recommended to improve these economic traits in egg weight using it has an index in selection and in possible prediction of the quality of poults to be hatched. Also, economically, it may be used to know the consumers' preference on the quality of turkey eggs consumed.

Keywords: External and internal egg quality, local turkey strains, Haugh units

\section{Une Évaluation des caractéristiques de qualité des oufs de deux souches de dinde locale (Meleagrisgallopavo) à Zaria, État de Kaduna}

\section{Résumé}

L'étude a été menée pour étudier les caractéristiques de qualité externe et interne des oufs de deux souches locales de dinde au début de leur âge de reproduction. Un total de 96 aufs fraîchement pondus ont été échantillonnés à partir de deux souches de dinde locales présentant des plumages noirs et blancs. Les dindes étaient âgées de 33 semaines avec deux mois de ponte. Des données ont été collectées chaque semaine pendant trois semaines sur le poids de l'œuf, la longueur de l'œuf, le diamètre de l'œuf, l'épaisseur de la coquille, le poids de la coquille, l'indice de la coquille, le poids de l'albumine, le poids du jaune, le rapport albumine: jaune, la longueur de l'albumen, la longueur du jaune, le diamètre de l'albumen, le diamètre du jaune, l'albumine hauteur, hauteur du jaune, indice de jaune et unité Haugh et analysés à l'aide du progiciel statistique de 'SAS'. Les résultats ont révélé que des différences très significatives $(p=0,01)$ dans les caractères externes se produisaient dans le poids des 


\section{Egg quality characteristics in two strains of local turkeys}

oufs, la longueur des oufs et le poids de la coquille avec la souche de dinde blanche supérieure. En outre, les traits internes ont enregistré des différences très significatives ( $p=$ $0,01)$ dans le poids de l'albumine, le poids du jaune, le rapport albumine : jaune, la longueur de l'albumine, la longueur du jaune et le diamètre du jaune, la souche blanche fonctionnant mieux que la souche noire. Des corrélations hautement significatives $(p<0,01)$ existent dans la plupart des traits corrélés avec l'unité à l'exception de Haugh qui n'avait pas de corrélations significatives $(p<0,01)$. Ainsi, étant donné que des variations importantes existent entre les deux souches, des activités de sélection sont recommandées pour améliorer ces caractères économiques en poids de l'ouf en utilisant un indice de sélection et de prédiction éventuelle de la qualité des dindonneaux à éclore. Aussi, économiquement, il peut être utilisé pour connaître la préférence des consommateurs sur la qualité des æuufs de dinde consommés.

Mots clés : Qualité des œufs externes et internes, souches de dinde locales, unités Haugh

\section{Introduction}

The production of poultry meat and eggs have grown faster than that of any other major food in the developing countries (FAO, 2010). The fast growth in turkey industry in Nigeria requires an intensive research approach to boast its production especially considering the potential associated with it. This has led to a number of farms breeding this bird at commercial level owing to increasing interest as a provider of meat complementing chicken (Adeoye et al., 2017); increasing population income, urbanization, and westernization of diets (Osama et al., 2013). Turkey is a profitable venture as long as the poults are properly fed and taken care of. They have less cost of production as almost $50 \%$ of their feed is green vegetables as they are foraging animals similar to ruminants (Soliven, 1984 and Schultz, 1981). Indigenous turkeys in Nigeria are unselected with either black, white and mixed colour strains. These strains are characterized by small body size when compared to selected strains and they have poor egg production of 2-3 clutch per year with between 10-15egg per clutch. They are indigenous to Nigeria with the rural dwellers as the primary producers. Body weight ranges from 7 to $8 \mathrm{~kg}$ in toms and 4 to $\mathrm{kg}$ in hen in average while under intensive system was $5249 \mathrm{~g}$ (tom) and $4597.30 \mathrm{~g}$ (hen) and in free-range system was $3448.73 \mathrm{~g}$ (tom) and 2933.82g (hen) at 10 weeks while at 18 weeks it was $12285.71 \mathrm{~g}$ (tom) and 10164.20g (hen) under intensive and for free-range it was 8438.18g (toms) and 6985.29g (hen) FAO (2004). The significance of egg as a protein source for the nourishment of humans has led to the consumer's demand for some nutritional qualities (Uluocak et al., 1995). Eggs and meat are amongst the most nutritious foods and eggs are rated with milk as one of the best protein foods. Eggs generally are rich in nutrients of iron, vitamins A, riboflavin, folic acid, vitamin B6, vitamin B12, choline, calcium, phosphorus and potassium along with 163 calories of energy per $100 \mathrm{~g}$ of egg and also, they contain essential amino acids (Oluyemi and Roberts 2000; Ahsan and Akhtar, 2002). Egg quality is then of serious concern as it defines the general standard of the internal and external qualities of egg weight, egg length, width, egg index, shell weight, shell thickness, albumin height, albumin width, yolk height, yolk index and Haugh unit (Bobbo et al., 2013) and its acceptability by consumers (Song et al., 2000). The external and internal egg quality traits are also significant in poultry breeding, especially for their influence on 
yield features of future generations, breeding performance, quality and growth of the chicks (Islam et al., 2001). Apparently, when management conditions and hen fertility are not a limiting factor on egg production systems, the egg quality characteristics affects the quality of the eggs (Khurshid et al., 2003). Ozcelik, (2002) used the morphological traits of eggs and the existing correlations among them for improving egg productivity and quality in quail selection. Similarly, the external and internal qualities are very important for consumer health and from a marketing perspective (Yenice et al., 2016) and the egg yield and quality are affected by a number of factors including husbandry system, age of hen, nutrition, breed/strain and environment (Ozbey and Esen 2007; RaduRusa et al., 2014). Therefore, it is empirical to evaluate the external and internal egg quality characteristics of these two local turkey strains in Zaria, Kaduna State for their qualities as there is dearth of information on these.

\section{Materials and methods Experimental location}

The study was conducted at the Teaching and Research Farm of the Department of Animal Science, Faculty of Agriculture, Ahmadu Bello University, Zaria, Nigeria. The farm is located at latitude $11^{\circ} 09^{\prime} 06^{\prime} \mathrm{N}$ and longitude $7^{\circ} 38^{\prime} 55^{\prime} \mathrm{E}$, at an altitude of $706 \mathrm{~m}$ above sea level (Ovimaps, 2019). The climate is relatively dry with a mean annual rainfall of $700-1400 \mathrm{~mm}$ occurring from late April to mid-October. The temperature varies from $26^{\circ} \mathrm{C}$ to $35^{\circ} \mathrm{C}$ depending on the season while the relative humidity during the hamattan period, hot and wet seasons are 21, 37 and $77 \%$ respectively (IAR, 2019).

Source of experimental birds and management

Twenty-eight (28) turkey hens approaching age of reproduction with fourteen (14) per strain (black and white plumages) were purchased from an open market in Gurbi, Zurmi Local government area of Zamfara State, Nigeria. The birds were initially quarantine for a period of two (2) weeks where they were monitored and given antibiotic medications against any possible infection. After which the birds were managed on deep litter system with each of the turkey in separate pens for proper identification and collection of data. The birds were fed with compounded feed meant for adult breeder turkey containing $3,350 \mathrm{Kcal} / \mathrm{kg}$ metabolizable energy and $17 \%$ crude protein. Feed and clean drinking water were supplied ad-libitum.

\section{Experimental design and data collection}

The twenty-eight turkey hens were randomly assigned into individual laying pens in a completely randomized design (CRD) for easy data collection. Data were collected for both external and internal egg characteristics on the same day of lay weekly for three weeks. The eggs were broken and the content emptied with the aid of a scalpel and petri-dish. The following parameters were determined:

Egg weight (g) was measured using a Camry sensitive digital weighing scale with accuracy of $0.01 \mathrm{~g}$ while the egg length and egg width $(\mathrm{mm})$ was taken using a Vernier caliper. The eggshell weight $(\mathrm{g})$ was taken after breaking the egg, and the content poured into a petri-dish. The eggshells were dried at room temperature and thereafter weighed using a Camry sensitive scale. Eggshell thickness $(\mathrm{mm})$ was measured using a micrometer screw gauge while the yolk depth, length and yolk width $(\mathrm{mm})$ for each egg were measured using Vernier caliper. The albumen depth, albumen width and albumen length $(\mathrm{mm})$ were also measured with Vernier caliper while the albumen and yolk weights were taken using the Camry sensitive digital weighing scale which was after separating the albumen from the yolk and their ratio calculated. The 


\section{Egg quality characteristics in two strains of local turkeys}

Haugh unit, yolk index, albumen index and egg shape index were calculated using the equations (Haugh 1937; Ukwu et al., 2017). Haugh unit $(\mathrm{HU})=100 \times \log (\mathrm{H}+7.6-$ $\left.1.7 \mathrm{~W}^{0.37}\right)$

Where $\mathrm{H}=$ albumen height $(\mathrm{mm})$ and $\mathrm{W}=$ egg weight $(\mathrm{g})$.

Yolk index $(\%)=\frac{\text { Yolk height }}{\text { Yolk diameter }} \times 100$

Albumen index $(\%)=$

Albumen height $\mathrm{x} 100$

Albumen length +Albumen width/2

Egg shape index $(\%)=$ Egg diameter $\times 100$

Statistical analysis

Egg length

Data collected from the study were subjected to one-way Analysis of Variance (SAS, 2002) and the differences between means were separated using the Duncan Multiple Range Test (Duncan, 1955). Pearson's product moment correlation was also performed using the same statistical package.

The appropriate statistical model used was: $\mathrm{Y}_{\mathrm{ijk}}=\mu+\mathrm{T}_{\mathrm{i}}+A \sigma_{\mathrm{j}}+\mathrm{e}_{\mathrm{ijk}}$

Where $\mathrm{Y}_{\mathrm{ijk}}=$ observation of the $\mathrm{k}^{\text {th }}$ error on the $j^{\text {th }}$ covariate of age effect on the $i^{\text {th }}$ strain of turkey.

$\mu=$ the overall common mean.

$\mathrm{T}_{\mathrm{i}}=$ the effect of $i^{\text {th }}$ parameter measured on each strain of turkey $(i=1,2)$.

$A \sigma_{j}=$ the covariate of the turkeys age.

$\mathrm{e}_{\mathrm{ijk}}=$ random error

\section{Results}

The mean values of external and internal egg quality characteristics obtained from two strains of local turkey at early reproductive age are presented in Tables 1 and 2 while their phenotypic correlations among the external and internal quality characteristics are shown in Tables 3 and 4. External egg quality characteristics showed significant $(\mathrm{p}<0.01)$ differences in egg weight, egg length and shell weight with the white strain been superior while traits of egg diameter, shell thickness and shape index had no significant $(p<0.01)$ difference. The results on the phenotypic correlation between the egg quality characteristics and the two local strains of turkeys are presented in Tables 3 and 4 for internal and external characteristics respectively. The internal characteristics showed that most of traits were positively significant and were low to highly $(\mathrm{p}<0.01)$ correlated as influenced by the strains. However, this was with the exception of Hhaugh unit that showed most of the traits not significantly correlated. Irrespective of the strains, positive and moderate to high significant correlations were observed in the external traits (egg length and egg diameters against other parameters) while most parameters with low to moderate significant correlations $(p<0.01)$ were observed in shell weight against other parameters. Also, significant but negative correlations was found between egg length and shell thickness $(r=-0.70)$, egg diameter and shell index $(\mathrm{r}=-0.66)$ and shell index and egg length $(r=-0.79)$. Insignificant correlations were observed in shell thickness against other parameters. With respect to strain, most of the significant correlations were showed to be related to the white strain in the external egg traits.

Table 1: External quality characteristics of eggs ( \pm SE) from two local strains of turkey lines

\begin{tabular}{|c|c|c|c|c|}
\hline Traits & Black strain & White strain & $\mathbf{C V}$ & P-value \\
\hline Egg weight (g) & $69.12 \pm 8.4^{\mathrm{b}}$ & $72.63 \pm 8.4^{\mathrm{a}}$ & 14.11 & 0.01 \\
\hline Egg length (mm) & $48.0 \pm 1.02^{\mathrm{b}}$ & $54.1 \pm 1.02^{\mathrm{a}}$ & 8.34 & 0.01 \\
\hline Egg diameter (mm) & $31.0 \pm 0.91^{\mathrm{ns}}$ & $30.8 \pm 0.9^{\mathrm{ns}}$ & 5.01 & 0.11 \\
\hline Shell thickness (mm) & $0.27 \pm 0.01^{\mathrm{ns}}$ & $0.27 \pm 0.02^{\mathrm{ns}}$ & 7.88 & 0.40 \\
\hline Shell weight (g) & $9.11 \pm 1.22^{\mathrm{b}}$ & $9.45 \pm 1.20^{\mathrm{a}}$ & 9.32 & 0.01 \\
\hline Shape index $(\%)$ & $64.58 \pm 2.51^{\mathrm{ns}}$ & $64.20 \pm 2.50^{\mathrm{ns}}$ & 1.31 & 0.11 \\
\hline
\end{tabular}


Table 2: Internal quality characteristics of eggs ( \pm SE) from two local strains of turkey lines

\begin{tabular}{lllll}
\hline Traits & Black strain & White strain & CV & P-value \\
\hline Albumen weight (g) & $38.47 \pm 4.08^{\mathrm{b}}$ & $39.95 \pm 4.10^{\mathrm{a}}$ & 2.08 & 0.01 \\
Yolk weight (g) & $22.36 \pm 1.58^{\mathrm{b}}$ & $23.24 \pm 1.60^{\mathrm{a}}$ & 4.82 & 0.05 \\
Albumen: Yolk ratio (\%) & $60.83 \pm 5.26^{\mathrm{b}}$ & $63.19 \pm 5.14^{\mathrm{a}}$ & 10.09 & 0.04 \\
Albumen length (cm) & $9.19 \pm 2.20^{\mathrm{b}}$ & $9.81 \pm 2.18^{\mathrm{a}}$ & 3.37 & 0.05 \\
Yolk length (cm) & $3.78 \pm 1.01^{\mathrm{b}}$ & $4.24 \pm 1.07^{\mathrm{a}}$ & 9.39 & 0.05 \\
Albumen diameter (cm) & $4.4 \pm 1.01^{\text {ns }}$ & $4.67 \pm 1.00^{\text {ns }}$ & 3.21 & 0.14 \\
Yolk diameter (cm) & $2.49 \pm 0.03^{\mathrm{b}}$ & $2.83 \pm 0.02^{\mathrm{a}}$ & 4.49 & 0.01 \\
Albumen height (cm) & $0.17 \pm 0.01^{\text {ns }}$ & $0.17 \pm 0.01^{\text {ns }}$ & 1.25 & 0.60 \\
Yolk height (cm) & $0.15 \pm 0.01^{\text {ns }}$ & $0.17 \pm 0.01^{\text {ns }}$ & 2.39 & 0.19 \\
Yolk index (\%) & $6.02 \pm 0.01^{\text {ns }}$ & $6.00 \pm 0.01^{\text {ns }}$ & 1.54 & 0.17 \\
Haugh unit & $146.70 \pm 1.40^{\text {ns }}$ & $146.84 \pm 1.40^{\text {ns }}$ & 5.94 & 0.21 \\
ab = means in the same column with different superscripts differ significantly $(\mathrm{p}<0.01)$, ns = not significant, \\
cv = coefficient of variation
\end{tabular}

Table 3: Phenotypic correlation between the internal egg quality characteristics of egg from two local strains of turkey lines with black strain (upper diagonal) and white strain (lower diagonal)

\begin{tabular}{llllllllll}
\hline Parameters & AW & AD & $\begin{array}{l}\text { A. } \\
\text { depth }\end{array}$ & YL & YW & YD & $\begin{array}{l}\text { Y. } \\
\text { depth }\end{array}$ & A: Y & HU \\
\hline AL & $0.42^{* *}$ & $0.74^{* * *}$ & 0.04 & $0.44^{* *}$ & $0.30^{*}$ & $0.37^{*}$ & 0.26 & 0.14 & -0.11 \\
AW & $0.55^{* *}$ & $0.42^{* *}$ & $0.47^{* *}$ & $0.33^{*}$ & $0.78^{* * *}$ & $0.43^{* *}$ & 0.23 & -0.26 & -0.07 \\
AD & $0.60^{* *}$ & $0.54^{* *}$ & -0.03 & 0.20 & $0.49^{* *}$ & 0.02 & $0.46^{* *}$ & -0.01 & -0.20 \\
A. depth & 0.21 & 0.39 & -0.07 & -0.04 & $0.53^{* *}$ & $0.67^{* * *}$ & $0.66^{* *}$ & -0.05 & $0.83^{* * *}$ \\
YL & $0.48^{* *}$ & $0.60^{* *}$ & 0.09 & -0.19 & $0.69^{* * *}$ & $0.30^{*}$ & $0.47^{* *}$ & $0.36^{*}$ & 0.24 \\
YW & 0.27 & $0.71^{* * *}$ & $0.42^{* *}$ & $0.44^{* *}$ & $0.84^{* * *}$ & $0.56^{* *}$ & $0.70^{* * *}$ & $0.59^{* *}$ & -0.08 \\
YD & $0.60^{* *}$ & $0.52^{* *}$ & $0.33^{*}$ & $0.54^{* *}$ & $0.39^{*}$ & $0.70^{* * *}$ & $0.30^{*}$ & $0.40^{* *}$ & 0.03 \\
Y. depth & 0.13 & 0.19 & $0.53^{* *}$ & $0.63^{* *}$ & $0.38^{*}$ & $0.52^{* *}$ & $0.39^{* *}$ & 0.03 & 0.011 \\
A: Y & 0.20 & -0.03 & 0.21 & -0.21 & $0.33^{*}$ & $0.64^{* *}$ & $0.53^{* *}$ & 0.12 & 0.031 \\
HU & 0.02 & 0.10 & -0.23 & $0.89^{* * *}$ & 0.13 & -0.17 & 0.14 & 0.04 & 1.00 \\
\hline
\end{tabular}

$* * * p<0.001,{ }^{* *} \mathrm{p}<0.01,{ }^{*} \mathrm{p}<0.05, \mathrm{AL}=$ Albumen length, Albumen weight, Albumen diameter, A. depth $=$ Albumen depth, Yolk length, YW= Yolk weight, YD=Yolk diameter, Y. depth, $\quad$ A: Y = Albumen: Yolk ratio, $\mathrm{HU}=$ Haugh unit

Table 4: Phenotypic correlation between the external egg quality characteistics of egg from two local strains of Turkey with black strain (upper diagonal) and white strain (lower diagonal)

\begin{tabular}{lllllll}
\hline Parameters & Egg weight & Egg length & Egg diameter & Shell thickness & Shell weight & Shell index \\
\hline Egg weight & 1.00 & $0.92^{* * *}$ & $0.84^{* * *}$ & $0.48^{*}$ & $0.33^{*}$ & -0.027 \\
Egg length & $0.84^{* * *}$ & 1.00 & $0.66^{* * *}$ & -0.04 & 0.30 & $-0.79^{* * *}$ \\
Egg diameter & $0.51^{* *}$ & $0.91^{* * *}$ & 1.00 & -0.03 & $0.46^{* *}$ & 0.21 \\
Shell thickness & $0.41^{*}$ & $-0.70^{* * *}$ & $0.46^{*}$ & 1.00 & $0.51^{* *}$ & $0.40^{* *}$ \\
Shell weight & $0.50^{* *}$ & $0.44^{*}$ & $0.56^{* *}$ & $0.61^{* * *}$ & 1.00 & $0.32^{*}$ \\
Shell index & 0.04 & -0.02 & $-0.66^{* * *}$ & 0.13 & $0.51^{* *}$ & 1.00 \\
\hline
\end{tabular}

$* * * p<0.001, * * p<0.01, * p<0$

\section{Discussion}

The egg weight and other weight traits associated with the egg of turkey agrees with the report of Genchev (2012) that egg weight traits are regarded as the most important egg quality trait. Thus, Marsden and Martin (1949) classified turkey eggs into seven groups as a function of weight, 


\section{Egg quality characteristics in two strains of local turkeys}

from very small (64 g) to very large (106 g). It can therefore be supposed that the two strains of turkey egg $(69.12 \mathrm{~g}$ and $72.63 \mathrm{~g})$ in this present study belong to the small to medium eggs group. In contrast to this result on egg weight is the report of Mroz et al. (2014) who reported a higher egg weight of $89.86 \mathrm{~g}$ during early laying phase in broad-breasted white turkeys breed with a continuous increase to $101.4 \mathrm{~g}$ at 23 weeks of lay implying that they fall under the classification of very large egg size. This may be attributed to the fact that these turkeys have undergone selection in which egg weight was part of the selection criteria. Adamski (2008) and Anandh et al. (2012) observed that too high a weight in turkey eggs are seen at the end of the laying cycle and are attributed to a positive relationship with the age of turkey hen. High variability of egg weight is associated with reduction in egg quality toward the end of the laying season Adamski (2008). The study of Nestor et al. (2008) revealed that when deliberate breeding efforts are introduced into turkey pedigree flock, it has led to increase in egg weights and other economic traits linked with eggs characteristics. The egg length values of this study varied largely between the strain however there was no such variations in egg diameter. This agreed with the reports of Mroz et al. (2014) on evaluation of laying seasons and classes of egg weight and with those of Galic et al. (2018) on laying cycles in Zagorje turkey. Also, the values obtained for egg length and diameter were similar to those reported in Ethiopian turkeys of $65.0 \mathrm{~mm}$ length and $47.0 \mathrm{~mm}$ width (Adeyeye, 2009) and slightly higher than average length and width of Nigerian turkey eggs, of 62.4 and $46.1 \mathrm{~mm}$, respectively (Popoola et al., 2015). The egg shell thickness has reported by Galic et al. (2018) is higher than the determined $0.27 \mathrm{~mm}$ in this study. Galic et al. (2018) also reported similar values of $0.356 \mathrm{~mm}$ in Poland turkey eggs of same weight class of 70 - 80g (Mroz et al., 2014), but lower compared with North Caucasian bronze turkey eggs, of $0.38-0.39 \mathrm{~mm}$ (Hristakieva et al., 2017a) and of heavy meat turkey eggs, of $0.43-0.44 \mathrm{~mm}$ (Hristakieva et al., 2009). The shell weight is usually not considered important although in circumstances where shell weight, shell percentage and shell thickness are good but shell breaking strength is relatively poor, the explanation probably lies with the shell ultrastructure, or how well the shell has been constructed (Roberts, 2004). The egg shape index as discussed by Hristakieva et al. (2017b) is a very essential parameter due to the role of egg shape in the direction of turning during incubation, which determines embryo movements for nutrient utilization. Sarica and Erensayin (2004) reported that turkey eggs can be characterized according to shape index (SI) as sharp, normal (standard) and round for SI values of $<72,72-76$, and $>76$, respectively. The average SI of $70.37 \%$ reported by Galic et al. (2018) in Zagorje turkey are comparable to those of local strain of turkey of this current study with $64.58 \%$ and $64.20 \%$ and therefore can be classified as shape. Likewise, the SI of Zagorje turkey eggs can be compared to those of North-Caucasian bronze turkey eggs with 71.57 - 74.25\% (Hristakieva et al., 2017a), heavy meat turkey eggs of 72.33 - 73.32\% (Hristakieva et al., 2009) and eggs of turkeys from India with 75.0 76.1\% (Anandh et al., 2012). Furthermore, the SI result of this study are similar to the $69.16-73.09 \%$ range reported by Mroz et al. (2014) at different laying season and egg weight class. The egg shape index values determined in this study are related with those reported by Faruga et al. (1996) and Adamski (2008) however, the values are lower than those reported in conservation flocks of turkeys (73.08\%) and in light-type broad-breasted turkeys (74.01-74.26\%). These dissimilarities are possible 


\section{Yahaya, Olutunmogun, Mohammad, Shettima and Kabir}

indications that egg shape index is affected by the origin of birds, breed or strain, selection efforts, variation in laying age and environmental differences (Adamski, 2008). The internal egg characteristics recorded significant $(\mathrm{p}<0.01)$ differences in albumen weight, yolk weight, albumen: yolk ratio, albumen length, yolk length and yolk diameter with the white strain been superior over the black while others internal traits record had no significant $(\mathrm{p}<0.01)$ difference between the two strains. In a general view, it was observed by TserveniGoussi and Fortomaris (2011) that the quality of turkey eggs with emphasizes on the internal characteristics does not differ from those of other avian species. Sinanoglou et al. (2011) reported that the variations in the moisture content of turkey, quail and goose edible egg yolks was less than $10 \%$ among each of the species. Studies on the internal quality characteristics of turkey eggs are limited to breeder eggs which agrees with the eggs used in this work has the eggs were meant for breeding and selection purposes since there is lack of commercial bred strains in the environment. This limitation is because the observed changes in these traits of quality are closely related to the egg fertility and embryo survival. The report of this study on albumen weight disagrees with the report of Applegate et al. (2005) were a much higher albumen weight of $52.64 \mathrm{~g}$ was reported as against 38.47 and $39.95 \mathrm{~g}$ for black and white strains respectively. This disparity is expected has commercial turkey egg were used by the authors as against the breeder stock of this current study. The result of this study for yolk weight is in line with the $24.18 \mathrm{~g}$ reported by Applegate $\mathrm{et} \mathrm{al}$. (2005) on commercial turkey however this variation exits because of the different genetic make-up of the strain. Furthermore, Reidy et al. (1994) reported that during the onset of lay to about 24 weeks, the yolk weight increases by $21 \%$ while the albumen weight by $7 \%$ depending on the genotype or strain of turkey. The albumen-yolk ratio of this study is similar with $53-62 \%$ reported by Applegate and Lilburn (1996) which was on a steady increase as age increased from $36-41$ weeks however disagrees Applegate et al. (1998) that obtained a slightly lower range of $50-58 \%$ in the initial 10 weeks of production. The difference was attributed to the use of different strain of different plumage which corroborate the differences observed in this study which could also be linked to strain effect. The yolk index and Haugh unit of this class of avian species studied were high and not significant irrespective of the strain which corroborates the report of Adeogun and Amole (2004) that the higher the Haugh unit and yolk index the more desirable is the interior quality of the eggs. The significant positive correlations reported between most of the egg quality traits in this study agrees with the report of Chimezie et al. (2017) and Ojedapo (2013) that reported significant positive correlations between egg quality traits in quails though very higher levels of correlation were reported in turkey eggs. The correlation between the egg weight and shell weight were low and moderate $(\mathrm{r}=$ 0.51 and $r=0.33)$ at $p<0.05,0.01$ in the two strains which corroborates the earlier findings (Choi et al., 1983; Oblakova, 2006; Hristakieva et al., 2017b) that provided evidence that the eggshell weight was positively influenced by the weight of the whole egg. A significantly but low positive correlation was found out between the egg weight and thickness in the two strains $(r=0.41$ vs $r=0.48$ black and white respectively) in eggs from turkeys at their early reproductive age. These positive correlations agree with the results of Hristakieva et al. (2017b) that also obtain positive significant correlation in these traits. This is important for determination of eggshell strength in breeder eggs. The nonsignificant correlation observed in the 


\section{Egg quality characteristics in two strains of local turkeys}

Haugh unit against the other internal egg characteristics of turkey eggs corroborate the findings of Chimezie et al. (2017) that reported in their findings a non-significant influenced by plumage colour on varieties of Japanese quail eggs. Also, the correlations were also negligible in Haugh unit and albumen - yolk ratio between all the internal traits and agrees with the reports of Chimezie et al. (2017). The findings of Chimezie et al. (2017) on Japanese quail varieties of plumage colours (black, brown and white) obtain significant correlations in most external traits which agrees with this present result. However, Chimezie et al. (2017) obtained no significant correlations in shell weight. The positive correlations among the internal and external characteristics therefore suggest that improvement in one lead to a positive improvement in the other which will lead to better quality of the eggs.

\section{Conclusion}

The two local turkey strains showed significant variations in traits of egg weight, egg length, shell weight, albumen weight, yolk weight, albumen: yolk ratio, albumen length, yolk length and yolk diameter. These variations can be employed in possible selection by including egg weight as an index in these unimproved strains of turkeys. The result can be used to improve choice of breeder eggs for quality hatched poults and economic traits of egg weight and egg qualities which will increase turkey egg consumer's preference for turkey eggs.

\section{Acknowledgement}

The authors acknowledge the support of the Head of department of Animal Science, Ahmadu Bello University, Zaria for releasing the facilities used to conduct this research. Also, the authors acknowledge those scholars whose articles are cited and included in references of this manuscript.

\section{Conflict of interest}

The authors have no conflict of interest what-so-ever to disclose.

\section{References}

Adamski, M. 2008. Relationships between the morphological composition of eggs and the hatchability of chicks of selected bird species. Dissertation submitted at the University of Technology and Life Sciences, Bydgoszcz, Poland. Page 130.

Adeogun, I. O. and Amole, F. O. 2004. Some quality parameters of exotic chicken eggs under different storage conditions. Bulletin of Animal Health and Production in Africa, 52: 43-47.

Adeoye, A. A., Rotimi, E. A. and Oluyode, M. O. 2017. Bi ometric differentiation of local and exotic turkeys (Meleagris gallopavo) in southwest Nigeria. Applied Tropical Agriculture, 22(2): 63-66.

Adeyeye, E. I. 2009. Comparative study on the characteristics of egg shells of some bird species. Bulletin of the Chemical Society of Ethiopia, 23(2): 159-166.

Ahsan, U. H. and Akhtar, M. 2002. Poultry farming. Publisher Higher Education Commission. Islamabad, Pakistan. Pages: 323324.

Anandh, M. A., Jagatheesan, P. N. R., Kumar, P. S., Rajarajan, G. and Paramasivam, A. 2012. Effect of egg weight on egg traits and hatching performance of turkey (Meleagris gallopavo) eggs. Iranian Journal of Applied Animal Science, 2(4): 391-395.

Applegate, T. J., Karcher, D. M. and Lilburn, M. S. 2005. Comparative development of the small intestine in the turkey poult and Pekin 
duckling. Poultry Science, 84(3): 426-431.

Applegate, T. J. and Lilburn, M. S. 1996. Independent effects of hen age and egg size on incubation and poult characteristics in commercial turkeys. Poultry Science, 75(10): 1210-1216.

Applegate, T. J., Harper, D. and Lilburn, M. S. 1998. Effect of hen production age on egg composition and embryo development in commercial Pekin ducks. Poultry Science, 77(11): 1608-1612.

Bobbo, A. G., Baba, S. S. and Yahaya, M. S. 2013. Egg quality characteristics of three phenotypes of local chickens in Adamawa State. Journal of Agriculture and Veterinary Science (IOSR-JAVS), 4(2): 13-21.

Chimezie, V. O., Fayeye, T. R., Ayorinde, K. L. and Adebunmi, A. 2017. Phenotypic correlations between egg weight and some egg quality traits in three varieties of Japanese quail (Coturnix coturnix japonica). Agro-Search, 17(1): 44-53.

Choi, J. H., Kang, W. J., Baik, D. H. and Park, H. S. 1983. A study on some characteristics of fractions and shell quality of the chicken egg. Korean Journal of Animal Science, 25: 651-655.

Duncan, D. B. 1955. Multiple range and multiple F tests. Biometrics, 11: 142.

Faruga, A., Pudyszak, K., Puchajda, H., Jankowski, J. and Kozłowski, K. 1996. Characteristics of eggs quality depending on the laying period and origin of turkeys. Scientific Notebooks of Breeding Review, 24: 91-99.

FAO. 2010. Food and Agriculture Organization (FAO). Statistical Reports, 1980-2010.
FAO. 2004. Food and Agriculture Organization (FAO). Small scale poultry production technical report. Manual of Animal Production and Health Manual, Page 15.

Galic, A., Pliestic, S., Janjecic, Z., Bedekovic, D., Filipovic, D., Kovacev, I. and Copec, K. 2018. Some physical, morphological and mechanical characteristics of turkey (Meleagris gallopavo) eggs. Brazilian Journal of Poultry Science, 20(2): 317-324.

Genchev, A. 2012. Quality and composition of Japanese quail eggs (Coturnix japaonica). Trakia Journal of Sciences, 10(2): 91-101.

Haugh, R. R. 1937. The Haugh unit for measuring egg quality. United States egg poultry. Mag., 43: 553555, 572-573.

Hristakieva, P., Oblakova, M. and Lalev, M. 2009. Incubation and vital morphological traits in eggs from age-related turkeys. Trakia Journal of Sciences, 7(1): 63-67.

Hristakieva, P., Oblakova, M., Mincheva, N., Lalev, M. Kaliasheva, K. 2017a. Evaluation of some eggshell parameters during the embryogenesis in turkeys. Slovak Journal of Animal Science, 50(1): 1-6.

Hristakieva, P., Oblakova, M., Mincheva, N., Lalev, M. and Kaliasheva, K. 2017b. Phenotypic correlations between the egg weight, shape of egg, eggshell thickness, weight loss and hatchling weight of turkeys. Slovak Journal of Animal Science, 50(2): 90-94.

IAR. 2019. Institute for Agricultural Research, Ahmadu Bello University, Zaria. Metrological Data Information of Samaru and its 


\section{Egg quality characteristics in two strains of local turkeys}

environs.

Islam, M. A., Bulbuli, S. M., Seeland, G. and Islam, A. B. 2001. Egg quality in different chicken genotypes in summer and winter. Pakistan Journal of Biological Science, 4: 1411-1414.

Khurshid, A., Faroog, M., Durrani, F. R., Sarbiland, K. and Chand, N. 2003. Predicting egg weight, shell weight, shell thickness and hatching weight of Japanese quail using various egg traits as regressors. International Journal of Poultry Science, 2: 164-167.

Marsden, S. J. and Martin, J. H. 1949. Turkey Management. In: Danville: The Interstate.

Mroz, E., Stepinska, M. and Krawezyk, M. 2014. Morphology and chemical composition of turkey eggs. Journal of Applied Poultry Research, 23: 196-203.

Nestor, K. E., Anderson, J. W., Patterson, R. A. and Velleman, S. G. 2008. Genetics of growth and reproduction in turkey. 17 changes in genetic parameters over forty generations of selection for increased sixteen-week body weight. Poultry Science, 87: 1971-1979.

Oblakova, M. 2006. Phenotypic correlations between some morphological characteristics of eggs in basic turkey lines at the age of 32 weeks. Bulgarian Journal of Agricultural Science, 12: 483-488.

Ojedapo, L. O. 2013. Phenotypic correlation between the external and internal egg quality traits of pharaoh quail reared in derived savanna zone of Nigeria. Journal of Biology, Agriculture and Healthcare, 3 (10).

Oluyemi, J. A. and Roberts, F. A. 2000. Poultry production in worm and wet climates. $2^{\text {nd }}$ Edition, spectrum B o o k s, I b a d a n, ISBN13:9789780290979, Page 190.

Osama, E. Y., Salim G., Al-Hafiz, A. H. and Bushara, A. B. 2013. A study on turkey (Meleagris Gallopavo) raising in the Sudan. Journal of Applied and Industrial Sciences, 1(4): 11-15.

Ovimaps, 2019. Ovilocation map; ovi earth imaginery. Dated August, 2018.

Ozbey, O. and Esen, F. 2007. The effects of different breeding systems on egg productivity and egg quality characteristics of Rock Partridges. Poultry Science, 86: 782-785.

Ozcelik, M. 2002. The phenotypic correlations among some external and internal quality characteristics in Japanese quail eggs. Veterinary Journal of Ankara University, 49: 67-72.

Popoola, M. A., Alemede, C. I., Aremu, A. and Ola, S. I. 2015. Morphometric parameters of whole egg and egg yolk of five Nigerian domesticated avian species. IOSR Journal of Agriculture and Veterinary Science, 8(3): 41-45.

Radu-Rusa, R. M., Usturoi, M. G., Leahu, A., Amariei, S., RaduRusu, C. G. and Vacaru-Opris, I. 2014. Chemical features, cholesterol and energy content of table hen eggs from conventional and alternative farming system. South African Journal of Animal Science, 44: 33-42.

Reidy, T. R., Atkinson, J. L. and Leeson, S. 1994. Strain comparison of turkey egg components. Poultry Science, 73: 388-395.

Roberts, J. R. 2004. Factors affecting egg internal quality and egg shell quality in laying hens. Journal of Poultry Science, 41: 161-177. 
SAS. 2002. Statistical Analysis System, Computer software, Version 9: Statistical SAS Institute Inc. Cary, Northern Carolina 27513, USA.

Sarica, M. and Erensayin, C. 2004. Poultry products. Ankara: Bey-of set.

Schultz, F. T. 1981. Potential of turkey in developing countries. Poultry International Zoology, (8):74.

Sinanoglou, V. J., Strati, I. F. and Miniadis-Meimaroglou, S. 2011. Lipid, fatty acid and carotenoid content of edible egg yolks from avian species: A comparative study. Food Chemistry, 124(3): 971-977.

Soliven, M. E. 1984. Rural turkey rearing in the Philippines. Poultry International, 23(6): 94.

Song, K. T., Choi, S. H. and Oh, H. R. 2000. A comparison of egg quality of pheasant, chukar, quail and guinea fowl. Asian-Australian Journal of Animal Science, 13: 986 $-990$.
Tserveni-Goussi, A. and Fortomaris, P. 2011. Improving the safety and quality of eggs and egg products: egg chemistry, production and consumption. Food Science, Technology and Nutrition, 509 537.

Ukwu, H. O., Ezihe, C. O., Asaa, S. K. and Anyogo, M. E. 2017. Effect of egg weight on external and internal egg quality traits of Isa Brown egg layer chickens in Nigeria. Journal of Animal Science and Veterinary Medicine, 2: 126-132. ISSN: 25367099.

Uluocak, A. N., Okan, F., Efe, E. and Nacar, H. 1995. Exterior and interior quality characteristics of eggs and their variation according to age in Japanese quail. Turkish Journal of Veterinary and Animal Science, 19: 181-185.

Yenice, G., Kaynar, O., Ileriturk, M., Hira, F. and Hayirli, A. 2016. Quality of eggs in different production system. Czech Journal of Food Science, 34(4): 370-376.

Received: $17^{\text {th }}$ September, 2020 Accepted: $20^{\text {th }}$ December, 2021 